\title{
Clarifying Differences Between Reading Skills and Reading Strategies
}

\section{Peter Afflerbach, P. David Pearson, Scott G. Paris}

There is a lack of consistency in the use of the terms skill and strategy, reflecting an underlying confusion about how these terms are conceptualized. Such inconsistency can confuse students and teachers and render instruction less effective.

$\mathrm{H}$ elping children learn to read is a deeply rewarding experience for parents and teachers who take pride as their children acquire effective reading skills and reading strategies. The terms skills and strategies are part of the vocabulary used by teachers to describe what they teach and what children learn. Yet, despite frequent use in professional discourse, the terms are used inconsistently. Sometimes skills and strategies are used as synonyms, and sometimes they are used to describe complementary relations (e.g., strategies support skills) or a notion of developmental progressions (e.g., first the phonics skills then the comprehension strategies). Policy makers, curriculum developers, administrators, and test makers include the terms when discussing reading programs, tests, goals, and policies, but they rarely define or distinguish the terms. Resolving the confusion is important because how we conceptualize and define reading skills and reading strategies has important implications for reading practices and reading policies.

The importance of learning to read has stimulated considerable debates-theoretical, practical, and political-about which teaching methods and materials are effective. During the past 10 years, the debates have become more strident as calls for school ac- countability have increased. The debates about teaching reading are not theoretical for teachers who are increasingly told by legislated policies what, how, and when to teach reading to students in their classrooms. The debates have also stimulated a greater reliance on scientific evidence by educational administrators and policymakers who want all teachers to use effective methods and materials (National Institute of Child Health and Human Development [NICHD], 2000; Snow, Burns, \& Griffin, 1998). Reading researchers, perhaps now more than ever before, have a responsibility to use the most relevant research to bridge theory and practice with coherent and useful models of reading development, curricula, instruction, and assessment. Toward this end, we want to discuss and clarify the distinctions between reading skills and reading strategies.

\section{In Search of Definitions}

Our exploration of reading skills and reading strategies begins with a brief discussion of existing conceptualizations and definitions and then considers the historical uses of the terms for clues about their similarities and differences. We consider developmental aspects of reading skills and strategies and suggest how these two related but different aspects of reading can be reconciled in a productive manner. We then describe implications of the distinction between skills and strategies for reading instruction and reading assessment.

Reading is a complex undertaking and an impressive achievement, as demonstrated by a century of research (Afflerbach \& Cho, in press; Huey, 1908; RAND Reading Study Group, 2002). At different historical times, reading has been defined by referring to specific skills such as reading the Bible, understanding direc- 
tions, or answering questions about text. More recently, strategies have been used to describe aspects of reading that involve intentional control and deliberate direction of behavior. Today, like many teachers and researchers, we use the terms skills and strategies, both formally and informally, to describe features of children's reading development as well as features of teachers' reading instruction (Paris, Wasik, \& Turner, 1991; Pressley \& Afflerbach, 1995). The term reading skills has been used in reading curricula for teachers and $\mathrm{K}-12$ students for at least 50 years. In contrast, the term strategies became popular in the 1970s to signify the cognitive aspects of information processing. Instead of reconciling the differences between skills and strategies, researchers, educators, and publishers simply grouped them together to be comprehensive. This phenomenon appears to be an act of convenience rather than a principled process. In our experiences, there are three main sources of confusion: diverse colloquial uses, inadequate definitions, and inconsistent use in formal documents.

Knowing that professionals who teach reading use the terms reading skill and reading strategy almost daily in their work, we began our inquiry by asking our colleagues (teachers, graduate and undergraduate education students, and professors of education) to tell us what each term meant and to describe how they might be related. Consider the variability in responses we received:

\section{"Skills make up strategies."}

"Strategies lead to skills."

"Skill is the destination, strategy is the journey."

"We learn strategies to do a skill."

"Skills are automatic, strategies are effortful and mediated."

"We use strategies as tools."

"Strategies that work require a skill set."

"We have to pay attention in learning skills, but eventually we use them automatically."

"You don't think about skills, and you do think about strategies."

The method and sample are limited, but we think that the responses illustrate several things. First, when asked, people are ready and willing to describe reading skills and strategies, and everyone seems confident in their own understanding. Second, the descriptions often characterize skill and strategy in relation to each other, but the type of relation is variable-it may be a precursor, companion, learning aid, and so forth. Third, there does not appear to be much shared understanding about the terms reading skill and strategy.

We followed our questioning of colleagues with consultation of The Literacy Dictionary (Harris \& Hodges, 1995), a commonly used reading reference, and found the following definitions:

skill $n$. 1. an acquired ability to perform well; proficiency. Note: The term often refers to finely coordinated, complex motor acts that are the result of perceptualmotor learning, such as handwriting, golf, or pottery. However, skill is also used to refer to parts of acts that are primarily intellectual, as those involved in comprehension or thinking. (p. 235)

strategy $n$. in education, a systematic plan, consciously adapted and monitored, to improve one's performance in learning. (p. 244)

These definitions are helpful, but they do not clarify thoroughly the distinctions between skills and strategies or the relations between them. In particular, note that skill is associated with the proficiency of a complex act, and strategy is associated with a conscious and systematic plan. These features may help differentiate the terms as we discuss them later.

Next, we searched the Internet for "reading standards" for clues about how professional organizations define skills and strategies. The website for the National Council of Teachers of English mentioned skills in the overview of the Standards for the English Language Arts (International Reading Association \& National Council of Teachers of English, 1996):

The vision guiding these standards is that all students must have the opportunities and resources to develop the language skills they need to pursue life's goals and to participate fully as informed, productive members of society. (n.p)

Strategies are mentioned in Standard 3:

Students apply a wide range of strategies to comprehend, interpret, evaluate, and appreciate texts. They draw on their prior experience, their interactions with other readers and writers, their knowledge of word meaning and of other texts, their word identification strategies, and their understanding of textual features (e.g., sound-letter correspondence, sentence structure, context, graphics). (n.p.) 
We also consulted an authoritative reading research source, the National Reading Panel Report (NICHD, 2000), and found the following account:

The rationale for the explicit teaching of comprehension skills is that comprehension can be improved by teaching students to use specific cognitive strategies or to reason strategically when they encounter barriers to understanding what they are reading. (p. 14)

To summarize, our search for clarity in current definitions and conceptualizations of reading skills and strategies yielded mixed results. Although researchers and educators think that skills and strategies are central to the development and success of reading it appears that the terms are used imprecisely and inconsistently. We think there is value in working toward consensus regarding the meanings of skill and strategy that distinguishes one from the other and that describes their commonalities and differences.

\section{Historical Clues to the Meanings of Skill and Strategy}

One source of confusion between skills and strategies is the different uses of the terms across time and disciplines. Skills has been used for a hundred years in both psychology and education, but the term refers to many types of behaviors and cognitions. The term strategies became popular in psychology with the advent of information-processing models, in which strategies, such as rehearsal, could be applied to information in short-term memory to preserve the information and move it into long-term memory (Atkinson $\&$ Shiffrin, 1968). Whether the cognitive processes were deliberate was not important for memory researchers, so the term strategies was not differentiated from skills or other processes for manipulating information mentally.

Information-processing models of memory helped developmental researchers investigate how memory improved as a function of age, intelligence, expertise, and other individual differences (Kail \& Hagen, 1977), whereas educational researchers studied various techniques that could enhance remembering, learning, and studying (Levin \& Pressley, 1986). For example, research on children's memory strategies in the 1970s investigated whether children produced and used memory strategies appropriately, effectively, and efficiently (e.g., Brown, 1978; Paris, 1978). At the same time, researchers examined children's developing awareness and control of thinking (i.e., metacognition) that might help children recruit and apply strategies more effectively (Flavell \& Wellman, 1977). In both types of research, the term strategies was used to describe the mental, and sometimes physical, actions that children could use to improve memory and other cognitive functions.

Thus, the use of strategies to describe children's information processing tactics was related to the emerging information processing theories of the 1970s. The strategies, however, were usually defined by examples, such as rehearsal, chunking, and imagery, rather than by explicit definitions of the scope, conscious use, or deliberate goal orientation of the actions. There was no account of the strategies used by accomplished readers or of the strategies that developing readers must learn. We agree with Alexander, Graham, and Harris (1998) that strategies represent intention: A reader who is strategic intends to use strategies to work toward a goal, be it comprehension of a textbook chapter, appreciation of a poem, or understanding instructions for assembling a bicycle. Intention, however, does not describe what the actions are, how they are learned, or how they can be taught.

The term skills in psychology was used in behavioral learning theories for most of the 20th century, and it had a history of reference to motor skills, routine habits, and activities that were less mindful and more automatic. Skills were rooted in behavioral descriptions of learning through practice, whereas strategies were rooted in constructive, self-controlled theories of information processing. Thus, even within psychology, the terms skills and strategies had different theoretical and historical origins.

In the field of reading, the term skills has a longer history of popular use than strategies, and the use was evident in published curricula and reading education in addition to research documents. The first mention we could find of the term skill in the professional literature was in The Twenty-Fourth Yearbook of the National Society for the Study of Education (Whipple, 1925). Skills were mentioned as the third aim in a curriculum for effective reading instruction-the first aim being elevating student's thinking power and tastes, and the second, developing motives and interests. Skills were equated with habits such as (a) recognizing units of thought (sentences), words, and typographic devices; (b) reading hygiene (proper light, 
distance from eyes, seating); or (c) oral and meaning interpretation. In examining the curriculum materials of the 1920s and 1930s, Smith (1965) noted that most of the series emerging from that era, including the widely used Curriculum Foundation Series of Scott Foresman, had begun to use the term skill to describe what had heretofore been labeled abilities; these phenomena included both general skills-such as comprehension, retention, organization, research, and interpretation—and specialized skills—such as understanding technical word meanings and reading math problems. Smith also found a delineation of comprehension skills cited in Pennel and Cusack (1929), (even though they were still labeled as habits):

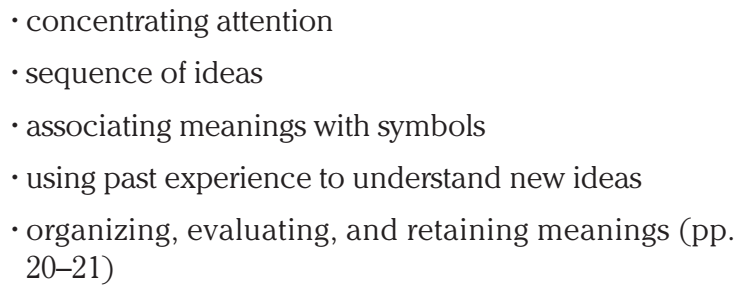

By the early 1940s, when Davis (1944) conducted the first psychometric analysis to determine "how many" comprehension skills there really were, he was able to cull nine candidates from his analysis of school reading curricula, and these are included in Table 1.

It is clear that a great deal of skill differentiation occurred in the two decades between the publication of The Twenty-Fourth Yearbook of the National Society for the Study of Education (Whipple, 1925) and Davis's work (1944). This differentiation continued throughout the 1940s, 1950s, and 1960s, reaching its peak in the proliferation of skills management systems in the 1970s, which was most vividly illustrated by the Wisconsin Design for Reading Skill Development (Otto, 1977; Otto \& Chester, 1976). The development program combined the systematic measurement and practice of isolated reading skills until individual student mastery was reached. Mastery was usually determined by scoring at least $80 \%$ correct on a skill test (Bloom, 1968). Once these skills emphasis management systems made their way into the basal readers of that era, their presence as a fact of life in everyday reading instruction went virtually unchallenged until the late 1980s and early 1990s when, for a brief halfdecade, they were banished from center stage. The discontent with skills began in the 1970s with the publication of articles like, "Skills Management Systems: A
Table 1

Davis's (1944) Componential Skills of Comprehension

Davis's nine potential component skills of comprehension

1. Word meanings

2. Word meanings in context

3. Follow passage organization

4. Main thought

5. Answer specific text-based questions

6. Text-based questions with paraphrase

7. Draw inferences about content

8. Literary devices

9. Author's purpose

Critique" (Johnson \& Pearson, 1975) and "Acquiring Literacy is Natural: Who 'Skilled' Cock Robin?" (Goodman, 1977/1982); but the real challenge to skills instruction came from the highly progressive, highly constructive models of pedagogy (in the form of whole language and literature-based reading) that held sway in the early 1990s.

This was followed by an even briefer period (roughly 1995-2001) of popularity for balanced literacy instruction, which included some skills but focused on constructing meaning (Pearson, 2004; Pressley, Almasi, Schuder, Bergman, \& Kurita, 1994). By the turn of the century, however, an enthusiasm for reading skills reemerged. With the advent of policies derived from No Child Left Behind and a strong emphasis on standards to guide instruction and tests to measure the impact of programs and interventions, reading skills have reached a status equal to their influence in the 1970s and 1980s.

Strategies entered everyday practice in classrooms when they became a part of basal instruction in the early to middle 1990s, riding the wave of a very popular line of instructional research suggesting their effectiveness (see Paris, Lipson, \& Wixson, 1983; Pearson \& Fielding, 1991; and Pressley, 2000, for articles summarizing the impact of this work). They are prominent in today's basal readers and are positioned alongside skills as a supportive but independent line of instruction. It is this independent relation between skills and strategies that, in our view, promotes confusion between the terms. 


\section{A Proposal for Conceptualizing Skills and Strategies}

We want to reduce the confusion. To that end, we offer an analysis that highlights the commonalities and distinctiveness of each term. Reading strategies are deliberate, goal-directed attempts to control and modify the reader's efforts to decode text, understand words, and construct meanings of text. Reading skills are automatic actions that result in decoding and comprehension with speed, efficiency, and fluency and usually occur without awareness of the components or control involved. The reader's deliberate control, goal-directedness, and awareness define a strategic action. Control and working toward a goal characterize the strategic reader who selects a particular path to a reading goal (i.e., a specific means to a desired end). Awareness helps the reader select an intended path, the means to the goal, and the processes used to achieve the goal, including volitional control (Corno, 1989) that prevents distractions and preserves commitment to the goal. Being strategic allows the reader to examine the strategy, to monitor its effectiveness, and to revise goals or means if necessary. Indeed, a hallmark of strategic readers is the flexibility and adaptability of their actions as they read. In contrast, reading skills operate without the reader's deliberate control or conscious awareness. They are used out of habit and automatically so they are usually faster than strategies because the reader's conscious decision making is not required. This has important, positive consequences for each reader's limited working memory system. Thus, as we consider a reader's actions, we must also determine whether they are under automatic or deliberate control. This is a key difference between skill and strategy.

It is important to note that reading strategies, like reading skills, are not always successful, and a definition of reading strategies does not entail only positive and useful actions. A young reader may choose an inappropriate goal, such as reading fast to finish before peers rather than reading carefully to understand the text. Some strategies are simply incorrect ideas about reading, such as guessing a word based on its initial letter. The actions are indeed strategic; they connect specific means to specific goals but they are inappropriate and ineffective for reading. Having good intentions and trying to be strategic are good starting points but neither alone ensures that readers will decode and understand text successfully. It is the appropri- ateness of the goal, the means, and the path to connect them that must be negotiated in every situation in order to be strategic and successful. This is fundamentally different than a skill that is well practiced and executed in the same manner across situations.

A concrete example may clarify the distinction. Suppose a student determines he or she has only a vague understanding of a paragraph as he or she reaches the end of it. The student wants to do something to clarify his or her comprehension so the student slows down and asks, "Does that make sense?" after every sentence. This is a reading strategy-a deliberate, conscious, metacognitive act. The strategy is prompted by the student's vague feeling of poor comprehension, and it is characterized by a slower rate of reading and a deliberate act of self-questioning that serves the student's goal of monitoring and building better comprehension. Now imagine that the strategy works and the student continues to use it throughout the school year. With months of practice, the strategy requires less deliberate attention, and the student uses it more quickly and more efficiently. When it becomes effortless and automatic (i.e., the student is in the habit of asking "Does that make sense?" automatically), the reading strategy has become a reading skill. In this developmental example, skill and strategy differ in their intentionality and their automatic and nonautomatic status.

The progression from effortful and deliberate to automatic use of specific actions while reading occurs at many levels-decoding, fluency, comprehension, and critical reading. Beginning readers need to associate visual patterns of letters with their phonemic pronunciations. A hoped for consequence of instruction is that students' decoding progresses from deliberate to fluent actions. Children in elementary school, especially when reading instruction focuses on constructing meaning, learn to find main ideas, to skim, and to reread first as deliberate actions and, with practice, later accomplish the same actions with less effort and awareness. In this view of learning, deliberate reading strategies often become fluent reading skills. Skills and strategies may serve the same goals and may result in the same behavior. For example, readers may decode words, read a text fluently, or find a main idea using either skills or strategies (or both). The distinction is often not very important to the student or teacher but across time movement from deliberate and effortful to fluent and automatic is a good thing. 
Practice alone may not be sufficient for some children to make this progress. Metacognitive instruction about how and why to use strategies can be quite effective (NICHD, 2000). Scaffolded and guided practice may also be required. Some readers may need to be persuaded that effective reading is one result of strategy use, and teachers may need to provide more explicit motivation to use and practice the strategies. In this view, fluent reading skills are more "advanced" actions than reading strategies because they are faster, more efficient, and require less thinking and social guidance. It is important, however, to promote both skilled and strategic reading because students need to know how to read strategically. Paris et al. (1983) described reading strategies as "skills under consideration" to denote that the same actions could be either a skill or strategy, depending on the readers' awareness, control, intention and the specific reading situation.

There are two specific situations in which it is useful to be a strategic reader. The first occasion to use appropriate strategies is during initial learning. As younger readers learn to associate letter shapes, names, and sounds, their teachers model specific strategies. Common examples are identifying the first letter of a child's name, pointing out aspects of letter shapes, or reciting the alphabet. Strategies for letter identification, decoding, oral reading, and comprehension can be embedded in dialogic reading with adults. They may seem basic and elementary, but early strategies, described, modeled, and supported by others, help children to direct their attention, choose actions, and decode print to sounds. A crucial part of reading development is the shifting control for using strategies-first in response to others and later as selfinitiated strategies. Fluent reading begins with strategies that integrate intentions, actions, and goals, and fluency increases with repeated practice.

Second, practice may help children develop fluent decoding, word recognition, and understanding, but when reading does not go smoothly, strategic intervention may be required. Careful reading and troubleshooting, prompted by a reader's metacognition, is a second occasion when strategic reading is required. For example, if a text includes many difficult words, convoluted syntax, and unfamiliar topics, or if a reading-related task is too challenging (e.g., summarize and then synthesize essays on the U.S. Civil War), students' usual skills may not work so decoding and comprehension may suffer. Strategic readers are aware of the specific difficulties and can generate alternative actions. For example, they may slow their reading rate, reread, or ask for help with new words. Strategic readers are problem solvers because they detect problems, are aware when their goals are not accomplished, and generate alternative means to reach their goals. Thus, troubleshooting, or cognitive monitoring and repair, is an essential aspect of strategic reading. In one sense, strategies compensate when usual skills fail.

There is a third, instructional counterpart to the previous situations: being metacognitive with explicit teaching — when teachers can explain, model, and use reading strategies. Teachers need to be able to break down successful reading into different parts so a learner becomes aware of the parts, understands how they work together, and practices combining the parts into the skilled performance that is reading. Vygotsky (1934/1978) referred to this cognitive disassembly as "defossilizing" (p. 63) a skilled action, and It is important,
however, to
promote both
skilled and
strategic reading
because students
need to know how
to read
strategically. it is not always easy for teachers to identify the components and determine the possible sources of difficulty that readers may encounter. Professional development activities can help teachers learn to conduct a detailed task analysis by which they understand the procedural knowledge underlying a skilled action. By analogy, it is like a perceptive sports coach who can diagnose subtle components of a complex motor skill and offer advice about what the athlete needs to change and how to coordinate the new actions.

It is necessary to provide support for students to become teachers. For example, if teachers use reciprocal teaching of reading strategies in pair-share activities, it may be necessary to help students understand how, when, and why specific strategies are effective. Classroom interventions that teach students how to be strategic readers include this metacognitive layer of discussion (e.g., Palincsar \& Brown, 1984; Paris, Cross, \& Lipson, 1984; Pressley et al., 1994). When students serve as teachers in pair-share or collaborative learning situations they need to understand how to disassemble and reassemble reading skills so that they can explain strategies to less skilled students and monitor 
the learner's use of the strategies. Teaching affords another opportunity for students to analyze their own use of strategies so teaching others can augment the students' own learning.

It is clear that students who learn about reading strategies can use the knowledge to become fluent and skilled, to monitor and make efficient their own reading, and to teach skills and strategies to others. This thoughtful and deliberate use of the strategies may also provide a motivational advantage for students. Reading skills are motivated by goals of fluency, effortlessness, and accuracy; they give rise to pride in ability not effort. Reading strategies are motivated by control, good decision making, and adaptability; they reinforce self-efficacy based on both ability and effort. Strategic readers feel confident that they can monitor and improve their own reading so they have both knowledge and motivation to succeed.

\section{Implications for Instruction and Assessment}

The implications for instruction are clear. We must provide explicit instruction about both skills and strategies. Traditional worksheets and frequent practice in reading easy texts (i.e., well within a student's comfort zone) may be sufficient to help many children practice basic skills such as letter recognition and phonemic awareness. Some struggling readers, however, may need to be taught specific strategies for visual and auditory discrimination so they know what to attend to, how to process it, and why it is necessary to disassemble and reassemble language sounds and word parts. In the same way, beginning readers may need to learn specific strategies to decode words and comprehend text. For example, identifying onset-rime patterns and decoding new words by analogy with familiar words can be taught and practiced deliberately as strategies when teachers model and guide young readers through the process. Teaching these kinds of reading strategies explicitly helps children understand what they are doing and why it is important- - two crucial features of learning that may escape children who are given daily worksheets to practice the skills without the cognitive explanations. Thus, even "basic" skills benefit from being taught as strategies initially, but the goal is fluent, proficient, automatic recognition of letters, phonemes, and words over time.
The dual emphasis on explicit teaching of skills and strategies is evident for comprehension too. We want children to easily recount, summarize, and critique texts without always having to use slow, deliberate strategies such as searching back in text and rereading. How can that be accomplished? Teachers need to explain how to think to their students; that is, we need to model, describe, explain, and scaffold appropriate reading strategies for children. For example, teachers can search for a main idea in a text and use thinking aloud to demonstrate their reasoning for each sentence and idea. They can describe the differences between a topic sentence and a main idea, differences between an explicit and implicit main idea, and differences between a main idea and supporting details in their discussion.

This is no easy task. As we teach, we may not understand our students' misconceptions about reading and may assume that an explanation delivered is an explanation understood. We may be challenged in diagnosing difficulties and "defossilizing" automatic skills. We may not be adept at making our thinking public (i.e., explaining how to think while reading). And we may not have the time in small-group instruction to add the layer of strategy instruction and metacognitive explanations that struggling readers need. But even with these barriers, we know it can be done. On a more positive note, we know that teachers who provide their students with strategies for taking responsibility for classroom roles (e.g., why we should be good and cooperative classroom citizens) are usually also very good at explaining strategies for decoding words and constructing meaning because they know the value of explicitly teaching different ways to accomplish a goal. Strategic teachers also set a precedent for intentional, self-regulated learning that spills over into reading instruction. Intentional strategies require that students take responsibility for their learning, and they also ensure that students attribute success to their efforts and strategies.

Reading instruction can follow a regular cycle of modeling, explaining, and guiding (all features of learning strategies) that leads to independent practice and fluency. If practice does not lead to fluency then more diagnostic and strategic teaching is warranted. Once the strategy has been learned and transformed into a fluent skill, teachers should introduce more challenging strategies and text. They should also provide opportunities for reteaching so that important 
strategies, such as making inferences, finding main ideas, and summarizing, are taught several times each year and repeated every year in $\mathrm{K}-8$ literacy instruction. The scope and complexity of these strategies are large, and there is ample variety of text difficulty and genre variety to practice so that the skills become automatic. The general rule is, teach children many strategies, teach them early, reteach them often, and connect assessment with reteaching.

It is important to note that the skill or strategy designation applies to a repertoire of actions or processes more than it does to readers. Developing readers certainly become more skilled just as athletes, artists, and cabinetmakers become more skilled. But there is always a text or a task lurking just beyond the horizon, waiting to humble any reader-even the most talented reader. In other words, readers should not be surprised (and should be prepared) when they encounter what we call "Waterloo" texts (after the downfall of Napoleon). These texts force the reader, however experienced, to revert to a highly strategic (i.e., deliberate, intentional, and step-by-step) journey through their pages. Thus, readers never outgrow the need to consult their strategy repertoire.

One key to effective strategy instruction is assessment, which enables teachers to introduce strategies that are on the leading edge of each child's reading proficiency. Teachers need to assess processes in both skilled and strategic mode. Measures of fluent decoding, retelling, and question answering are typically used to assess reading skills, but teachers may be unsure what to do if a child scores poorly on such skills. The answer is to assess the strategies. If a child cannot retell a story, ask the child to identify the order of key events or use a graphic organizer to query if the child understands narrative elements and their relations. If children cannot answer multiple-choice questions quickly, ask them to think aloud as they read the stem and response options and ask them to show you how they search for confirming or disconfirming evidence in the text. Experienced teachers know how to diagnose "dis-fluency" and the lack of proficiency by checking the strategies that children should be using. The main reason for assessing strategies is to find clues about what the student is not doing or what is being done incorrectly so that teachers can reteach better strategies. Strategy assessments are formative, and skill assessments are summative. If we use skill assessments for diagnostic teaching or fail to assess strat- egy use so children are given repeated cycles of the same instruction and the same assessments, we should not be surprised that children find this frustrating and unhelpful.

Unfortunately, teachers are rarely trained to assess children's reading in a strategic mode (Afflerbach, Ruetschlin, \& Russell, 2007), and there are few commercial resources for assessing strategies. That is why most strategy assessments are informal and embedded in instruction. Shared reading, guided reading, and small-group reading all provide opportunities for teachers to assess students' strategies, but it takes an insightful teacher to diagnose a child's problem from a specific error. That is why asking students to explain their thinking during or after reading provides such important insights for both teachers and students.

\section{Clearing the Confusion Between Skill and Strategy}

We have identified a need to distinguish between reading skills and strategies, provided an historical account of the use of the terms, provided examples of the distinctions between reading skills and strategies, and discussed implications for instruction and assessment. We conclude by revisiting our major points and adding some additional commentary.

It is important that the terms skill and strategy be used to distinguish automatic processes from deliberately controlled processes. At the heart of accomplished reading is a balance of both-automatic application and use of reading skills, and intentional, effortful employment of reading strategies-accompanied by the ability to shift seamlessly between the two when the situation calls for it. The difficulty of the reading, influenced by text, task, reader, and contextual variables, will determine this shifting balance. When their knowledge is strong and they are given easy text and goals, students can apply their usual skills. In contrast, when their knowledge is sketchy, texts are difficult, and reading tasks are complex, more strategic reading is required. The distinction between reading skill and strategy is important for understanding how readers learn new skills, how they repair difficulties while reading, and how they teach others to read. While automatic and fluid application of reading skills is a goal of instruction, we must remember that a particular reading skill is often preceded by a period in which the developing reader must be strate- 
gic. Young readers must learn decoding strategies before they can be expected to apply them accurately and automatically. Developing readers must learn to be metacognitive, and it is in the stage of conscious application of strategies that readers come to understand how reading works and how to identify and fix problems.

Readers are motivated to be skillful because skill affords high levels of performance with little effort, whereas strategic readers are motivated to demonstrate control over reading processes with both ability and effort. When skill and strategy complement each other, they can provide student readers with motivation and self-efficacy from both sources (I am good at this and I can work through the tough spots) and encourage an appreciation of the value of reading. In the final analysis, when we examine the broader goals of reading and examine reading holistically, we want readers to be both skilled and strategic. To characterize students as skilled readers is to recognize that they can orchestrate a wide array of processes to make reading work effortlessly. To characterize students as strategic readers is to recognize that they are flexible and adaptable to particular circumstances, and, when the situation calls for it, they can select just the right strategy to overcome any temporary roadblock they might encounter.

When we are teaching strategically, we help students to analyze tasks, to consider various approaches to performing the task, and to choose among alternative actions to reach the goal. Teaching skills involves practice and feedback to improve speed and efficiency, which taken together amount to what we call fluency. One challenge for teachers of reading is fully investigating the strategy-skill connection and determining how an effortful strategy can become an automatic skill. A related challenge is designing instruction that makes clear the steps of strategies while providing practice so that strategies may transform themselves into skills.

We are convinced that the current lack of consistency in use of the terms reflects an underlying confusion about how skill and strategy are conceptualized. Such inconsistency can render our instruction less effective, even confusing, to our students and to us. Consistent conceptualization and use of the terms skill and strategy will have several benefits. First, a clearer conceptualization provides a common language with which to discuss and reflect on the considerable infor- mation that is available from the research, practice, and theory related to skill and strategy. Second, it contributes to instructional clarity in which the teaching materials and procedures refer to a consistent set of understandings. Third, we can achieve a certain curricular economy if we regard skills and strategies as two "sides" of any given process or task; this perspective of "commonality" could limit the proliferation of "standards" to teach and measure that often results when we add more independent elements to any curriculum. Fourth, this clarity situates our understanding of skill and strategy in an historical context-one marked by the dynamic of new knowledge generated by research, and one that is subject to ongoing discussion and revision.

\section{Afflerbach teaches at the University of Maryland, College Park, USA; e-mail afflo@umd.edu.Pearson teaches at the University of California at Berkeley, USA; e-mail ppearson@berkeley.edu. Paris teaches at the University of Michigan, Ann Arbor, USA; e-mail paris@umich.edu.}

\section{References}

Afflerbach, P., \& Cho, B. (in press). Identifying and describing constructively responsive comprehension strategies in new and traditional forms of reading. In S. Israel \& G. Duffy (Eds.), Handbook of reading comprehension research. Mahwah, NJ: Erlbaum.

Afflerbach, P., Ruetschlin, H., \& Russell, S. (2007). Assessing strategic reading. In R. McCormack \& J. Paratore (Eds.), Classroom literacy assessment: Making sense of what students know and do (pp. 177-194). New York: Guilford.

Alexander, P., Graham, S., \& Harris, K. (1998). A perspective on strategy research: Progress and products. Educational Psychology Review, 10, 129-154.

Atkinson, R.C., \& Shiffrin, R.M. (1968). Human memory: A proposed system and its control processes. In K. Spence \& J. Spence (Eds.), The psychology of learning and motivation: Advances in research and theory (Vol. 2, pp. 89-195). New York: Academic.

Bloom, B.S. (1968). Learning for mastery. Evaluation Comment, $1(2)$.

Brown, A.L. (1978). Knowing when, where, and how to remember: A problem of metacognition. In R. Glaser (Ed.), Advances in instructional psychology (pp. 77-165). Hillsdale, NJ: Erlbaum.

Corno, L. (1989). Self-regulated learning: A volitional analysis. In B.J. Zimmerman \& D.H. Schunk (Eds.), Self-regulated learning and academic achievement (pp. 111-141). New York: SpringerVerlag.

Davis, F.B. (1944). Fundamental factors of comprehension of reading. Psychometrika, 9, 185-197.

Flavell, J.H., \& Wellman, H.M. (1977). Metamemory. In R.V. Kail \& J.W. Hagen (Eds.), Perspectives on the development of memory and cognition. Hillsdale, NJ: Erlbaum.

Goodman, K. (1982). Acquiring literacy is natural: Who skilled Cock Robin? In F. Gollasch (Ed.), Language \& literacy: The se- 
lected writings of Kenneth S. Goodman (Vol. 2, pp. 243-249). London: Routledge. (Original work published 1977)

Harris, T., \& Hodges, R. (1995). The literacy dictionary: The vocabulary of reading and writing. Newark, DE: International Reading Association.

Huey, E. (1908). The psychology and pedagogy of reading. Cambridge, MA: MIT Press.

International Reading Association \& National Council of Teachers of English. (1996). Standards for the English language arts. Newark, DE; Urbana, IL: Authors. Retrieved June 28, 2007, from www.ncte.org/about/over/standards/110846.htm

Johnson, D.D., \& Pearson, P.D. (1975). Skills management systems: A critique. The Reading Teacher, 28, 757-764.

Kail, R.V., \& Hagen, J.W. (Eds.). (1977). Perspectives on the development of memory and cognition. Hillsdale, NJ: Erlbaum.

Levin, J.R., \& Pressley, M. (Eds.). (1986). Learning strategies [Special issue]. Educational Psychologist, 21 (1 \& 2).

National Institute of Child Health and Human Development. (2000). Report of the National Reading Panel. Teaching children to read: An evidence-based assessment of the scientific research literature on reading and its implications for reading instruction (NIH Publication No. 00-4769). Washington, DC: U.S. Government Printing Office.

Otto, W. (1977). The Wisconsin design: A reading program for individually guided elementary education. In R.A. Klausmeier, R.A. Rossmiller, \& M. Saily (Eds.), Individually guided elementary education: Concepts and practices (pp. 216-237). New York: Academic.

Otto, W.R., \& Chester, R.D. (1976). Objective-based reading. Reading, MA: Addison-Wesley Higher Education.

Palincsar, A.S., \& Brown, A. (1984). Reciprocal teaching of comprehension-fostering and comprehension-monitoring activities. Cognition and Instruction, 1, 117-175.

Paris, S.G. (1978). Coordination of means and goals in the development of mnemonic skills. In P. Ornstein (Ed.), Memory development in children (pp. 259-273). Hillsdale, NJ: Erlbaum.

Paris, S.G., Cross, D.R., \& Lipson, M.Y. (1984). Informed strategies for learning: A program to improve children's reading awareness and comprehension. Journal of Educational Psychology, 76, 1239-1252.

Paris, S.G., Lipson, M.Y., \& Wixson, K. (1983). Becoming a strategic reader. Contemporary Educational Psychology, 8, 293-316.
Paris, S.G., Wasik, B.A., \& Turner, J.C. (1991). The development of strategic readers. In R. Barr, M.L. Kamil, P. Mosenthal, \& P.D. Pearson (Eds.), Handbook of reading research (Vol. 2, pp. 609-640). White Plains, NY: Longman.

Pearson, P.D. (2004). The Reading Wars. Educational Policy, 18 , 216-252.

Pearson, P.D., \& Fielding, L. (1991). Comprehension instruction. In R. Barr, M.L. Kamil, P. Mosenthal, \& P.D. Pearson (Eds.), Handbook of reading research (Vol. 2, pp. 815-860). White Plains, NY: Longman.

Pennell, M.E., \& Cusack, A.M. (1929). The children's own readers, books four, five, and six [Teachers' manual]. Boston: Ginn \& Company.

Pressley, M. (2000). What should comprehension instruction be the instruction of? In M.L. Kamil, P. Mosenthal, R. Barr, \& P.D. Pearson, (Eds.), Handbook of reading research (Vol. 3, pp. 545-562). Mahwah, NJ: Erlbaum.

Pressley, M., \& Afflerbach, P. (1995). Verbal protocols of reading: The nature of constructively responsive reading. Hillsdale, NJ: Erlbaum.

Pressley, M., Almasi, J., Schuder, T., Bergman, J., \& Kurita, J.A. (1994). Transactional instruction of comprehension strategies: The Montgomery County Maryland SAIL program. Reading and Writing Quarterly, 10, 5-19.

RAND Reading Study Group. (2002). Reading for understanding: Toward an $R \& D$ program in reading comprehension. Santa Monica, CA: RAND.

Smith, N.B. (1965). American reading instruction. Newark, DE: International Reading Association.

Snow, C.E., Burns, M.S., \& Griffin, P. (Eds.). (1998). Preventing reading difficulties in young children. Washington, DC: National Academy Press.

Vygotsky, L.S. (1978). Mind in society: The development of higher psychological processes (M. Cole, V. John-Steiner, S. Scribner, \& E. Souberman, Eds. \& Trans.). Cambridge, MA: Harvard University Press. (Original work published 1934)

Whipple, G. (Ed.). (1925). The twenty-fourth yearbook of the National Society for the Study of Education: Report of the National Committee on Reading. Bloomington, IL: Public School Publishing Company. 